\title{
Diabetes Complication
}

National Cancer Institute

\section{Source}

National Cancer Institute. Diabetes Complication. NCI Thesaurus. Code C84415.

Organ or tissue damage due to diabetes mellitus. It includes heart disease and stroke, renal disease and renal failure, retinopathy, neuropathies, and erectile dysfunction. 